\title{
ENHANCING BANK SUPERVISION IN ASIA: LESSONS LEARNED FROM THE FINANCIAL CRISIS
}

Michael J. Zamorski and Minsoo Lee

NO. 443

August 2015
ADB ECONOMICS WORKING PAPER SERIES 


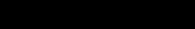

ADB Economics Working Paper Series

\section{Enhancing Bank Supervision in Asia: Lessons Learned from the Financial Crisis}

Michael J. Zamorski and Minsoo Lee

No. 443 | August 2015
Michael J.Zamorski (mzamorski@seacen.org) is Adviser on Financial Stability and Supervision of the South East Asian Central Banks (SEACEN) Research and Training Centre. Minsoo Lee (mlee@adb.org) is Senior Economist in the Economic Research and Regional Cooperation Department of the Asian Development Bank. 
Asian Development Bank

6 ADB Avenue, Mandaluyong City

1550 Metro Manila, Philippines

www.adb.org

(C) 2015 by Asian Development Bank

August 2015

ISSN 2313-6537 (Print), 2313-6545 (e-ISSN)

Publication Stock No. WPS 157550-2

The views expressed in this paper are those of the authors and do not necessarily reflect the views and policies of the Asian Development Bank (ADB) or its Board of Governors or the governments they represent.

ADB does not guarantee the accuracy of the data included in this publication and accepts no responsibility for any consequence of their use.

By making any designation of or reference to a particular territory or geographic area, or by using the term "country" in this document, $A D B$ does not intend to make any judgments as to the legal or other status of any territory or area.

Note: In this publication, "\$” refers to US dollars.

The ADB Economics Working Paper Series is a forum for stimulating discussion and eliciting feedback on ongoing and recently completed research and policy studies undertaken by the Asian Development Bank (ADB) staff, consultants, or resource persons. The series deals with key economic and development problems, particularly those facing the Asia and Pacific region; as well as conceptual, analytical, or methodological issues relating to project/program economic analysis, and statistical data and measurement. The series aims to enhance the knowledge on Asia's development and policy challenges; strengthen analytical rigor and quality of ADB's country partnership strategies, and its subregional and country operations; and improve the quality and availability of statistical data and development indicators for monitoring development effectiveness.

The ADB Economics Working Paper Series is a quick-disseminating, informal publication whose titles could subsequently be revised for publication as articles in professional journals or chapters in books. The series is maintained by the Economic Research and Regional Cooperation Department. 


\section{CONTENTS}

ABSTRACT

$\begin{array}{ll}\text { I. INTRODUCTION } & 1\end{array}$

II. CAUSES OF THE 2007-2008 CRISIS AND THE NEED FOR ENHANCED SUPERVISION 1

III. THE BASEL COMMITTEE'S CORE PRINCIPLES FOR EFFECTIVE SUPERVISION 3

$\begin{array}{llr}\text { A. } & \text { Assessment Methodology } & 4 \\ \text { B. } & \text { Rationale for 2012 Revisions } & 4 \\ \text { C. } & \text { Self-Assessment } & 5\end{array}$

IV. LESSONS LEARNED FROM THE 2007-2008 CRISIS

A. Bank Supervision Was Too Weak 5

B. Bank Supervision Needs to Be Timely and Proactive 6

C. Off-Site Surveillance of Banks Helps Identify Potential Problems 7

D. Macroprudential Policy Should Be Used to Control Systemic Risk 7

E. Other Lessons $\quad 9$

V. THE FINANCIAL SECTOR ASSESSMENT PROGRAM 10

VI. THE CHALLENGE OF PROVIDING CONSOLIDATED SUPERVISION OF FINANCIAL AND BANKING CONGLOMERATES

VII. CRISIS MANAGEMENT, RECOVERY, AND RESOLUTIONS 12

VIII. CONCLUSIONS AND RECOMMENDATIONS

$\begin{array}{ll}\text { REFERENCES } & 17\end{array}$ 


\begin{abstract}
The global financial crisis underlined that sound and effective bank regulation is vital to financial stability. Assessments of the global financial crisis invariably point to ineffective finance regulation and supervision as the main reasons for the onset of the crisis and its severity. In particular, lapses in banking regulation contributed significantly to the outbreak. The crisis reflected the failure of regulatory authorities to keep pace with financial innovation. Bank supervision had been weak by any measure. Supervisors did not conduct regular onsite bank inspections or examinations of sufficient depth. They did not properly implement risk-based supervision, and they failed to identify shortcomings in banks' risk-management methods, governance structures, and risk cultures. Meanwhile, offsite surveillance systems rely too heavily on banks' self-reported data to effectively monitor risk. Banking regulation is the primary safeguard against financial instability, but it should be supplemented by macroprudential policies and other new policy instruments now available to regulatory authorities.
\end{abstract}

Keywords: Basel Committee's core principles, finance regulation and supervision, global financial crisis, macroprudential policy

JEL Classification: G01, G18, G21, G28 


\section{INTRODUCTION}

Financial integration in emerging Asia increased over the past decade, as close linkages across economies developed. Regional initiatives to create more competitive, open, and internationalized finance sectors - such as the Association of Southeast Asian Nations (ASEAN) Banking Integration Framework-reinforced this trend. ${ }^{1}$ A key priority is to ensure that regulatory and supervisory regimes support this changing environment by controlling the related risks to financial stability.

This paper highlights the key attributes of effective supervision and regulation needed to enable emerging Asia's banking systems to support sound, sustainable growth and development. The analysis considers lessons learned from the 2007-2008 financial crisis in the United States (US) and Europe, insights from the International Monetary Fund (IMF)/World Bank Financial Sector Assessment Program (FSAP), the features and context of emerging Asia's banking industry, and postcrisis efforts to reform and enhance international bank regulatory and supervisory standards and practices.

\section{CAUSES OF THE 2007-2008 CRISIS AND THE NEED FOR ENHANCED SUPERVISION}

The crisis caused central bankers and regulators around the world to reflect on several questions:

(i) What were the root causes of the crisis?

(ii) Why did regulators and policy makers fail to see the crisis coming, especially given its severity and wide-ranging and systemic effects?

(iii) With the passage of time and opportunity for reflection, what lessons were learned for national authorities and policy makers seeking to avoid future crises?

In an attempt to offset the adverse economic effects of the financial crisis and stimulate economic growth, many central banks, particularly in the advanced economies at the epicenter of the crisis, lowered policy rates to zero or near zero. They also implemented other accommodative policy measures, such as quantitative easing. The resultant ultralow interest rate environment in many markets induced a global search for yield among investors. Significant capital flowed into emerging markets, including emerging Asia, where higher returns were available and economic growth prospects more favorable.

Economies receiving sizable amounts of foreign investors' funds have to carefully manage the risks of these potentially volatile capital inflows, which can cause unsustainable asset price inflation in local markets. They also need to be prepared for the possibility of substantial capital flow reversals when investor sentiment changes and better returns become available elsewhere. In countries where capital inflows fuel rapid rises in asset prices, bank supervisors need to ensure that institutions' lending decisions, particularly for commercial and residential real estate mortgages, are based on borrowers' sustainable cash flow/repayment capacity and not on the presumption of continuing increases in the value of real estate collateral.

\footnotetext{
ASEAN central bank governors endorsed the ASEAN Banking Integration Framework in April 2011 (Wihardja 2013).
} 
Effective bank regulation and supervision is critical to ensuring that stable and resilient banks are well positioned to meet the productive credit needs of their customers and allow depositors to accumulate savings, which provides a stable funding source for loan portfolio growth. A sound banking system is one in which problems are manageable. If failures do occur, they are not large or systemic, and their overall impact is small. Banks and other regulated financial intermediaries remain willing and able to meet prudent requests for credit.

A key goal of supervision is the reduction of systemic risk. A 2001 Group of 10 (G-10) report on finance sector consolidation describes systemic financial risk as "the risk that an event will trigger a loss of economic value or confidence in, and attendant increases in uncertainty about, a substantial portion of the financial system that is serious enough to quite probably have significant adverse effects on the real economy" (BIS 2001, 126).

A joint report by the IMF, the Bank for International Settlements (BIS), and the Financial Stability Board describes systemic risk as the "risk of disruption to financial services that is (a) caused by an impairment of all or parts of the financial system and (b) has the potential to have serious negative consequences for the real economy." "Fundamental to this definition is the notion of negative externalities from a disruption or failure in a financial institution, market, or instrument. "All types of financial intermediaries, markets, and infrastructure can potentially be systemically important to some degree" (IMF, BIS, and FSB 2009, 2).

The regulatory and financial stability reform agendas being pursued by international standardssetters such as the Financial Stability Board and the Basel Committee on Banking Supervision are intended to both reduce the probability that banks will fail and mitigate the costs of failures and preserve public confidence in the banking system should failures occur.

The direct and indirect costs of financial crises are typically very high. Adverse impacts to the real economy include curtailment of economic output, constrained availability of credit, and declines in asset values. Laeven and Valencia (2012) analyze banking, currency, and sovereign debt crises between 1970 and 2011. They identify 134 systemic banking crises during this 42-year period and quantify the economic impact (see table below). ${ }^{3}$

2 "The Financial Stability Board was established in April 2009 as successor to the Financial Stability Forum." Its mandate is to serve as "a mechanism for national authorities, standard setting bodies and international financial institutions to address vulnerabilities and to develop and implement strong regulatory, supervisory and other policies in the interest of financial stability" (www.financialstabilityboard.org/about/history). A comprehensive description of the FSB's various initiatives is available at http://www.financialstabilityboard.org

3 They consider a banking crisis to be systemic if there are "significant signs of financial distress in the banking system (as indicated by significant bank runs, losses in the banking system, and/or bank liquidations)" and "significant banking policy intervention measures in response to significant losses in the banking system" (Laeven and Valencia 2012, 4). The complete data set is available at www.imf.org/external/pubind.htm 
Median Outcomes of Banking Crises, by Type of Economy, 1970-2011

\begin{tabular}{|lcccc|}
\hline Indicators & All & Advanced & Emerging & Developing \\
\hline Output loss (\% of GDP) & 23.0 & 32.9 & 26.0 & 1.6 \\
Increase in debt (\% of GDP) & 12.1 & 21.4 & 9.1 & 10.9 \\
Monetary expansion (\% of GDP) & 1.7 & 8.3 & 1.3 & 1.2 \\
Fiscal costs (\% of GDP) & 6.8 & 3.8 & 10.0 & 10.0 \\
Fiscal costs (\% of financial system assets) & 12.7 & 2.1 & 21.4 & 18.3 \\
Duration (years) & 2.0 & 3.0 & 2.0 & 1.0 \\
Peak liquidity (\% of deposits and foreign liabilities) & 20.1 & 11.5 & 22.3 & 22.6 \\
Liquidity support (\% of deposits and foreign & & & 11.1 & 12.3 \\
liabilities) & 9.6 & 5.7 & 30.0 & 37.5 \\
Peak nonperforming loans (\% of total loans) & 25.0 & 4.0 & & \\
\hline
\end{tabular}

GDP = gross domestic product.

Source: Laeven and Valencia (2012).

\section{THE BASEL COMMITTEE'S CORE PRINCIPLES FOR EFFECTIVE SUPERVISION}

The BIS, located in Basel, Switzerland, is owned by the world's central banks and monetary authorities. ${ }^{4}$ It seeks to promote international cooperation among central banks and other regulators and global financial stability.

Toward those ends, it sponsors various finance sector regulatory and supervisory standardsetting committees, which identify and promulgate sound regulatory and supervisory practices and standards. These committees cover the supervision and regulation of the banking, insurance, and securities (capital markets) industries; payment and settlement systems; and cross-sectoral financial stability issues. Committee members include top regulators and policy makers from member jurisdictions. Although the committees' pronouncements do not have the force of law, as the BIS and its sponsored committees have no supranational supervisory or regulatory authority, their expert consensus pronouncements commonly form the basis of countries' finance sector laws, regulations, and policies.

The Basel Committee on Banking Supervision (BCBS or Basel Committee), founded in 1974, is the oldest of the BIS standard-setters. It provides a forum for cooperation on supervisory matters, develops international standards and sound practices for the global banking industry, and encourages convergence toward common approaches.

It is perhaps best known for its development and promulgation of international capital standards. But it has also performed ground-breaking work in identifying the preconditions for effective bank supervision programs. These conditions are embodied in the "Core Principles for Effective Supervision" (known as the Basel Core Principles, or BCP).

The BCP were first issued in 1997 and revised in 2006 and 2012. The 2012 BCP enumerate 29 Core Principles (CPs) that identify infrastructure, minimum standards, and approaches to an effective

4 This section is adapted from Zamorski (2013a). 
bank supervision program. The BCP provide a framework against which bank regulatory authorities can benchmark their bank supervision programs through self-assessments. The IMF and World Bank use the $\mathrm{BCP}$ to assess the effectiveness of jurisdictions' bank supervision regimes during their FSAP reviews.

The $\mathrm{BCP}$ represent important preconditions for an effective supervisory system. However, the ultimate test of supervisory effectiveness is whether a prudential supervisor's actual practices in implementing the $\mathrm{BCP}$ and the regulator's supervisory culture result in the detection and curtailment of imprudent risk-taking or other unsound practices at their incipient stages. The effectiveness of the BCP also depends on the existence of basic supportive national circumstances and infrastructure, such as political stability, the rule of law, property rights, and credible accounting and financial reporting standards.

\section{A. Assessment Methodology}

The BCP detail the specific criteria for assessing CP compliance, the definition of the grading system, and practical considerations in conducting assessments. Each CP is intended to apply to the prudential supervision of all banks, ranging from small deposit-taking institutions to large, complex, internationally active banks. The $\mathrm{BCP}$ recognize that supervisory resources should be allocated in proportion to the risk profile and systemic importance of banks (BCBS 2012a).

Assessment criteria have been specified for each CP. They are designated as either "Essential Criteria" ("minimum baseline requirements for sound supervisory practices universally applicable to all countries") or "Additional Criteria" ("supervisory practices that exceed current baseline expectations but will contribute to the robustness of individual supervisory frameworks") (BCBS 2012, 7-8). Compliance is assessed on a four-grade scale: compliant, largely compliant, materially noncompliant, and noncompliant. FSAP BCP assessments grade compliance based only on the "Essential Criteria," though a jurisdiction can voluntarily choose to be assessed against the "Additional Criteria" as well.

\section{B. Rationale for 2012 Revisions}

The objective of the 2012 BCP revisions was to maintain their relevance as global standards of good practice by incorporating lessons learned from the US/eurozone crisis of 2007-2008 and feedback from the FSAP process. ${ }^{5}$ Revisions of the CP assessment criteria reflect the need for

(i) greater supervisory intensity and adequate resources to deal effectively with systemically important banks;

(ii) application of a systemwide, macro perspective to the microprudential supervision of banks, to assist in identifying, analyzing, and taking preemptive action to address systemic risk; and

(iii) sharper focus on effective crisis management, recovery, and resolution measures in order to reduce the probability and impact of bank failures (BCBS 2012b).

The revised $\mathrm{BCP}$ were restructured to make clearer what bank supervisors need to do and what they expect banks to do. CPs 1 through 13 address supervisory powers, responsibilities, and functions. They focus on effective risk-based supervision and the need for early intervention and timely

5 The revised BCP are available at www.bis.org/publ/bcbs230.htm 
supervisory actions. CPs 14 through 29 address the supervisory expectations of banks. ${ }^{6}$ They emphasize the importance of good corporate governance and risk management, as well as compliance with supervisory standards (BCBS 2012).

A new CP was added for corporate governance, reflecting its importance in ensuring institutional and systemic stability. It emphasizes that corporate governance is the responsibility of banks' boards and senior management. Two other new CPs significantly expand coverage of supervisory independence, powers, transparency, and cooperation, which were previously covered in a single CP. They recommend greater public disclosure and transparency and enhanced financial reporting and external audit.

\section{Self-Assessment}

The BCBS encourages bank supervisory authorities "to move towards the adoption of updated and new international supervisory standards as they are issued” (BCBS 2012, 5). Bank supervisors should coordinate with other relevant national authorities to conduct self-assessments using the revised BCP. Some jurisdictions have publicly disclosed their BCP self-assessments in the interest of transparency and accountability.

When internal and external BCP assessments disclose less than full compliance with individual CPs, remedial action should be pursued to achieve full compliance. Such action may require changes in laws, rules, regulations, procedures, policies, and/or supervisory practices. The BCBS issued a paper in 2001 to help jurisdictions produce comprehensive, credible, and action-oriented self-assessments of their supervisory systems.

\section{LESSONS LEARNED FROM THE 2007-2008 CRISIS}

Assessments of the financial crisis identified long lists of contributing factors. The most important factors are discussed here. ${ }^{7}$

\section{A. Bank Supervision Was Too Weak}

Ineffective finance sector regulation and supervision contributed to both the onset and severity of the crisis. Some of the most frequently cited supervision-related causes include the following:

(i) laxity in allowing banks to operate with excessive leverage;

(ii) failure to curtail unsafe and unsound lending, primarily residential real estate mortgages to subprime borrowers, that was based on the "support" provided by perceived collateral values, without realistic property appraisals or verification and analysis of borrowers' repayment capacity;

6 Early intervention refers to banking laws, such as "prompt corrective action" (PCA) statutes that require bank supervisors to place increasingly stringent operating restrictions on undercapitalized banks as their capital declines. The general objective of PCA is to close nonviable institutions or transfer their operations to new ownership well before book capital is zero or negative, in order to minimize losses to deposit insurers, depositors, and other creditors. Restrictions can include dividend prohibitions, curtailment of nondeposit borrowings or asset growth, and executive compensation limitations.

7 This section is adapted from Zamorski (2012). 
(iii) failure to conduct regular on-site supervisory inspections or examinations at reasonable intervals and in sufficient depth;

(iv) improper implementation of the concept of risk-based supervision; ${ }^{8}$

(v) failure to identify ineffective bank risk management methods and governance structures and shortcomings in bank risk cultures;

(vi) overemphasis on institutions' historic operating results and static financial conditions in assessing risk, without fully considering potential vulnerabilities;

(vii) overreliance on off-site surveillance systems, which rely on banks' self-reported data, to monitor bank risk;

(viii) failure to understand the risks and policy implications of new bank products and services and changing bank business models; and

(ix) ineffective communications/information-sharing between domestic and foreign supervisors.

Analyses by the IMF, the Financial Stability Board, and the Basel Committee identified additional causal factors:

(i) failure to adequately monitor and control macroprudential risks (monitoring that focused on the risks in individual institutions failed to consider that a build-up of macroeconomic risks and vulnerabilities could adversely affect multiple institutions simultaneously, posing systemic risk);

(ii) analytical approaches that focused too narrowly on financial modeling, in some cases with unrealistic inputs and assumptions and without adequate analysis and interpretation of model outputs;

(iii) failure to conduct comprehensive stress testing of the banking system and other economic sectors, including low-probability/high-impact scenarios;

(iv) insufficient attention to concentrations of risk and interdependencies, including crossborder risks; and

(v) failure to consider risks in the shadow banking industry or cross-sectoral risks posed by nonbank financial intermediaries. ${ }^{9}$

\section{B. Bank Supervision Needs to Be Timely and Proactive}

For bank supervision to be effective, it must be timely, proactive, anticipatory, and forward looking. It must detect potential problems early. There is no substitute for a regular program of on-site examinations or inspections conducted by experienced professional bank examiners who perform a reasonable level of transaction testing.

On-site interactions with bank management provide examiners with the opportunity to understand a bank's risk management capabilities and assess the quality and depth of its executive management team and the quality of oversight provided by its board of directors. Corporate governance and risk management competencies are a key part of examiners' forward-looking analyses to assess the resiliency of a bank to the onset of unfavorable business conditions. When unacceptable

8 Risk-based supervision refers to the allocation of finite supervisory resources to the greatest areas of banks' perceived risk. In the context of an on-site supervisory examination, it refers to preplanning and risk-scoping examinations that focus efforts on the most important risk areas.

9 The FSB describes shadow banking as parts "of the financial system that extend credit but are outside the regular banking sector." FSB (2013) contains a comprehensive discussion of shadow banking and associated financial stability risks. 
practices or conditions are disclosed during an examination, bank supervisors need to ensure that the bank takes timely remedial action.

Bank supervisors need to be aware of banks' changing business strategies and product offerings as close to real time as possible, in order to practice proactive supervision and prevent problems. Banks can modify their strategies and risk appetite quickly, changing their overall risk profile. These changes may not be immediately detectible through off-site monitoring techniques. Bank business strategies and product offerings may change, possibly creating excessive risks or raising other concerns that call for the issuance of timely guidance from regulators.

There are no universally accepted standards or guidelines regarding the priority, frequency, and scope of on-site examinations. Practices vary across jurisdictions, but annual full-scope on-site examinations, supplemented by interim regulatory reporting, seem to be common.

In an attempt to be more proactive, some regulators conduct "thematic reviews," which entail selecting a sample of banks and conducting on-site reviews of a particular issue or risk area. (A thematic review could be conducted for commercial real estate lending, for example.) Bank examiners review individual institution's practices and follow up on areas of concern. Common concerns emanating from all of the reviews could form the basis for an industry alert or policy guidance from regulators to try to control these risks proactively, as some banks might not be scheduled to receive a near-term examination.

\section{Off-Site Surveillance of Banks Helps Identify Potential Problems}

Off-site surveillance of banks is based on periodic (usually at least quarterly) unaudited/unverified self-reporting of their financial positions and operating results to regulators and the public using standardized data sets. There can be significant time lags between financial reporting dates and public availability of the data (which promotes market discipline), though regulators typically have earlier access.

Off-site surveillance is not a substitute for on-site examinations, though it enables analysis of the level and trend of key financial ratios and peer group comparisons, which are important in detecting red flags and identifying outliers. This information can then be used to prioritize on-site examination activities and allocate examiner resources to the areas of greatest perceived risk. Some regulators have developed proprietary monitoring systems that attempt to predict changing bank risk profiles and ratings based on the level and trend of key financial ratios and peer group comparisons.

\section{Macroprudential Policy Should Be Used to Control Systemic Risk}

The crisis underscored the urgent need for national bank supervisory authorities to improve surveillance systems to detect, at their incipient stages, the build-up of macroeconomic risks, vulnerabilities, or threats that could jeopardize the stability of the financial system. ${ }^{\circ}$ Macroprudential policies are designed to safeguard systemic financial stability. They consist of measures that can be taken, alone or in concert with other policy actions, to avert, dampen, or mitigate periods of instability or crisis. To safeguard systemic financial stability, macroprudential policy requires a rich set of

10 This section is adopted from Zamorski (2013b). 
instruments to prevent and mitigate financial stability risks - related to credit, liquidity, and capital risks - stemming from vulnerabilities building up in the broader financial system."

The BCBS is increasingly guided by the need for a macroprudential perspective in financial regulation. Much progress has been made on the regulatory front, especially with the Basel III rules on the quantity and quality of bank capital (e.g., countercyclical capital buffers). Macroprudential policy aims to enhance the system's resilience to shocks and to limit the build-up of systemic risk. Efforts are directed toward identifying systemic risks to financial markets, strengthening the resilience of the financial system to preserve financial stability, and avoiding a recurrence of another crisis.

Macroprudential policy measures fall into three broad categories (Lim et al. 2011):

(i) credit controls (caps on the loan-to-value ratio, the debt-to-income ratio, and foreign currency lending as well as ceilings on credit or credit growth);

(ii) regulation of liquidity (limits on net open currency positions or currency mismatches, limits on maturity mismatches, and reserve requirements); and

(iii) capital requirements (countercyclical capital requirements, time-varying/dynamic positioning, and restrictions on profit distribution).

Macroprudential tools (such as minimum capital ratios and loan-to-value ratios) have been used for some time. Having dealt with previous threats to financial stability, especially from volatile capital flows, Asian countries have experience implementing a variety of macroprudential measures to prevent or address asset price bubbles or other threats to financial stability.

Emerging economies, mostly bank-dominated economies, with less developed financial systems tend to face greater challenges in managing the consequences of the procyclicality of financial system and cross-border financial linkages. The use of macroprudential measures in advanced economies and emerging markets depends on the economy's financial structure and the characteristics of the financial market (Claessens, Ghosh, and Mihet 2013).

The macroprudential approach has a time dimension and a cross-sectional dimension. In the time dimension, the source for system-wide distress can be the procyclicality of the financial system: financial institutions and markets overexpose themselves to risks in the upswing of the financial cycle and then become overly risk averse in the downswing, leaving the entire financial system and economy vulnerable to booms and busts. The cross-sectional dimension of systemic risk arises from the interconnectedness of financial institutions and markets: the actions and problems of individuals or financial institutions can have spillover effects on the overall financial system. Given their interconnectedness, the contemporary market-based finance sector should be thought of as including not only deposit-taking, loan-making commercial banks but also investment banks, money market funds, insurance companies, and potentially even hedge funds and private equity funds.

Operationalizing macroprudential policies is a challenge given that it is largely a judgmental process, albeit one informed by empirical analyses. Moreover, even if macroprudential policy measures appear to achieve desired policy objectives, it can be difficult to establish the efficacy of policy actions.

1 The scope of macroprudential policy covers banking, insurance, pension funds, financial infrastructures, and shadow banking. 
Responsibility for implementing various macroprudential measures may reside in different national authorities. Monetary, fiscal, and tax policies can affect systemic risk. Policy actions therefore require close cooperation and coordination by domestic authorities to ensure that they do not have contradictory goals or offset one another.

The BCBS (2012) notes that "the recent crisis highlighted the interface between, and the complementary nature of, the macroprudential and microprudential elements of effective supervision." Macroprudential approaches and methods do not supplant microprudential activities, especially the need to conduct on-site examinations at reasonable intervals that include an appropriate level of transaction testing. There is also a need for off-site surveillance systems that allow ongoing monitoring of industry trends and identification of outliers through peer group comparisons and other analytical methods. As Jaime Caruana (2012), the general manager of the BIS, has pointed out, macroprudential policy tools "are inadequate in the absence of effective and at times intrusive supervision: the incentives for regulatory arbitrage are simply too powerful." Indeed, a conglomerate could avoid the impact of a jurisdiction's macroprudential policy actions by moving activities to a subsidiary in a jurisdiction that has not implemented such measures. Cross-border coordination of policy actions might prevent such regulatory arbitrage, though doing so may be difficult given differing national circumstances.

\section{E. Other Lessons}

One of the most comprehensive and insightful sources of detailed information about the root causes of US bank failures and the performance of bank supervisors before and during the crisis is contained in the material loss reviews (MLRs) conducted by inspectors general for US banking supervisory authorities - the Federal Reserve Board of Governors; the Department of the Treasury (the regulator for federally chartered banks, the Office of the Comptroller of the Currency [OCC], is part of Treasury); and the Federal Deposit Insurance Corporation (FDIC). The inspectors general are nominated by the president of the United States and confirmed by the US Senate; they are operationally independent of the agencies whose activities they oversee. Their mandate is to conduct performance audits of agency operations. MLRs are prepared for bank failures resulting in significant losses to FDIC or failures that involve unusual circumstances.

In 2013 FDIC Inspector General Jon T. Rymer testified before the US Senate Committee on Banking, Housing, and Urban Affairs regarding the agencies' MLR findings about the financial crisis, in which more than 400 US banks failed, and some of the country's largest institutions required governmental intervention. Factors for the failures cited in the MLR included the following:

(i) aggressive bank growth strategies,

(ii) concentrations of asset (mostly loans) risks,

(iii) poor loan underwriting standards,

(iv) deficient credit administration practices, and

(v) precipitous declines in real estate values (commercial real estate values fell more than $42 \%)$.

In his testimony Rymer stated:

In response to unprecedented circumstances, the regulators generally fulfilled their supervisory and resolution responsibilities as defined by statutes, regulations accounting standards, and interagency guidance in 
place at the time.... However, material loss review findings... showed that the FRB [Federal Reserve Board], OCC, and FDIC could have provided earlier and greater supervisory attention to troubled institutions that ultimately failed.

\section{THE FINANCIAL SECTOR ASSESSMENT PROGRAM}

The IMF and the World Bank conduct periodic assessments of member countries' overall financial stability through the FSAP (IMF 2014a). These reviews began in 1999, after the 1997-1998 Asian financial crisis and other costly and disruptive episodes of financial instability and banking system crises, many of which involved multiple jurisdictions (IMF 2014b).

The severity of the crisis caused the IMF and the World Bank to evaluate whether precrisis FSAPs adequately identified risks and vulnerabilities, given lessons learned from the authorities' performance in handling the crisis. Based on this review, in 2009 they revised the FSAP program to achieve "more systematic, candid, and transparent" financial stability assessments. ${ }^{12}$

As of August 2014, 144 member-countries had requested and undergone FSAPs, most of them more than once. The IMF conducts 14 to 16 FSAPs a year, at an annual cost of $\$ 13$ million to $\$ 15$ million (IMF 2014a).

FSAPs are an important part of the IMF's ongoing surveillance activities, providing independent assessments of the strength and resiliency of countries' economies and financial system infrastructure. ${ }^{13}$ They are based primarily on on-site missions and other field work performed by experienced teams of trained assessors, including subject matter experts in various aspects of financial stability.

Mandatory FSAP assessments are conducted at least once every 5 years for the 29 jurisdictions deemed to have systemically important finance sectors (IMF 2014a). The IMF publishes the results in its Financial System Stability Assessment reports, accessible on its website. ${ }^{14}$

Although the coverage and scope of FSAPs are similar, they are not identical. They are tailored to a country's stage of economic development and the composition, size, and complexity of its banking system and financial markets. FSAPs typically address countries' current macroeconomic conditions,

12 Key revisions included closer analysis of linkages between the broader economy and the finance sector; coverage of a wider variety of sources of risk; presentation of a Risk Assessment Matrix in FSAP reports; and greater emphasis on crosscountry links, spillover effects, and coordination arrangements.

13 The views expressed in FSAP reports are based on the information available at the time they were completed. The views expressed are those of the staff and do not necessarily reflect the views of the government of the jurisdiction being assessed or the Executive Board of the IMF. FSAP reports contain a qualification similar to the following: "FSAP assessments are designed to assess the stability of the financial system as a whole and not that of individual institutions. They have been developed to help countries identify and remedy weaknesses in their finance sector structure, thereby enhancing their resilience to macroeconomic shocks and cross-border contagion. FSAP assessments do not cover risks that are specific to individual institutions, such as asset quality, operational or legal risks, or fraud."

14 A searchable index of FSAP and ancillary reports issued since 2001 is available at www.imf.org/external/np/fsap/fsap.aspx. This page also contains links to the IMF documents that provide an in-depth discussion of the FSAP process and related matters. The IMF surveillance and FSAP assessment activities for a jurisdiction are sometimes conveyed in multiple reports, each providing detailed assessments of a particular risk area or conformity to international standards and practices. FSAP findings may incorporate or reference the findings of these reports in an overall country assessment that is presented in a Financial System Stability Assessment report, commonly referred to as an FSAP report. 
performance during the crisis, recent economic performance and future prospects, systemic resiliency to internal and external shocks, and whether finance sector supervision and regulation meet international standards.

FSAP reports contain a wide variety of findings, conclusions, and recommendations for remedial action, reflecting the diverse characteristics of the jurisdictions reviewed. The FSAP report is the core country assessment document. Multiple supporting documents provide more detailed analyses and commentary.

The FSAPs usually emphasize the following issues:

(i) macroeconomic and macroprudential stress testing,

(ii) compliance with BCP and the soundness of actual supervisory practices,

(iii) crisis preparedness and resolution, and

(iv) countries' financial stability self-assessments.

Many countries conduct periodic financial stability self-assessments, using criteria and approaches similar to those used in the FSAP. Self-assessments inform policy makers about potential risks and vulnerabilities to financial stability. They also consider whether a jurisdiction's infrastructure and approaches to promoting financial stability meet international standards.

\section{THE CHALLENGE OF PROVIDING CONSOLIDATED SUPERVISION OF FINANCIAL AND BANKING CONGLOMERATES}

The past 20 years have seen the emergence and expansion of many large banking conglomerates throughout emerging Asia. Some of these institutions operate systemically important banks in more than one country. The structures of companies providing banking and other financial services continues to evolve as institutions seek to expand their geographic reach and achieve economies of scale and scope as restrictions on banks' affiliations and permissible activities are relaxed or removed in many countries.

Some banking organizations are part of large, multitiered conglomerates with complex organizational/ownership structures. Organizational structures include financial conglomerates that provide traditional banking services (focused on deposit-taking and lending) as well as other financial services, such as insurance, securities brokerage, and investment banking. Banking organizations may also be affiliated with, or owned by, commercial enterprises (such organizations are known as mixedactivity conglomerates). Some of these conglomerates' subsidiaries or activities may be unregulated.

Gaps in supervisory oversight, unregulated activities, and other opacities within a financial conglomerate may inhibit the timely detection of financial weaknesses or excessive risks. Various mechanisms, such as intercompany transactions, can allow problems in one part of a conglomerate to rapidly spread and infect other parts. Such contagion risk can affect the financial soundness of bank subsidiaries.

Banking conglomerates typically identify, measure, monitor, and control risk on a consolidated group basis. Consolidated risk profiles can obscure potential weaknesses or contagion risk within a banking group, however. Although conglomerates' subsidiary banks have the same controlling owners, they have different depositors and creditors, to whom their boards of directors have legal/fiduciary 
responsibilities. ${ }^{15}$ The directors of affiliated banks must determine that affiliate transactions are in the best interests of the bank they serve and do not jeopardize the safety of depositors' funds.

Affiliated banks' capital and liquidity are not fungible; funds cannot be moved around within a conglomerate at will. To prevent the transmission of problems throughout a banking group, many jurisdictions have well-defined rules governing affiliate transactions. These rules may include restrictions on the movement of capital, such as dividend limitations, and stringent requirements for loans between and among affiliated banks, including conservative limits on amounts and requirements for collateral in excess of the loan amount (for example, $120 \%$ of the loan), to protect against declines in collateral values.

Banking conglomerates or individual banks may move activities or risks off their balance sheets to other legal entities within a banking group or to sister banks or other affiliates in different jurisdictions, including unregulated entities, in order to evade or circumvent legal prohibitions or take advantage of less stringent (or no) legal requirements, laxer supervision, or even the absence of oversight of certain activities. Adoption of international standards and harmonization of regulatory practices will help prevent regulatory arbitrage.

Bank supervisors need to fully understand the risks posed by affiliate relationships, in order to have a holistic and forward-looking view of potential threats and vulnerabilities to the safety and soundness of affiliated banks. The size of some of these organizations and/or their interlinkages may make them systemically important in multiple jurisdictions.

Bank supervisory authorities in jurisdictions where conglomerates operate subsidiary banks need to ensure timely and effective two-way communication and information-sharing with their foreign counterparts. Coordination among supervisors enables better understanding of the risks and financial soundness of the conglomerate's parent and its bank and nonbank subsidiaries, as well as the risks posed by transactions between and among affiliated organizations.

The IMF has expressed concerns about widespread weaknesses in countries' execution of consolidated supervision identified during their FSAP country reviews. Given the significance of large banking conglomerates in emerging Asia and ongoing financial integration, national authorities should perform joint self-assessments of countries' compliance with the "Essential Criteria" of CPs 12 and 13 of the 2012 BCP. ${ }^{16}$

\section{CRISIS MANAGEMENT, RECOVERY, AND RESOLUTIONS}

The 2012 BCP consider material weaknesses in supervisory methods and vulnerabilities that came to light during the crisis. One such area is banks' and regulatory authorities' state of readiness with respect to crisis management, recovery, and resolution measures. The Basel Committee has stated that

15 Legal definitions of "control" vary across jurisdictions but typically specify a threshold percentage of ownership deemed to constitute control. In the US, for example, $25 \%$ ownership of voting stock may constitute control. However, the determination of whether control exists may require the bank supervisory agency to make subjective judgments. For example, a group of individuals may have individual stockholdings below the specified control threshold, but they may be deemed to be exercising control if their combined ownership exceeds the control threshold because the supervisor has determined that they are "acting in concert."

16 These assessment criteria can be found at www.bis.org/publ/bcbs230.htm 
preventing bank failures should not be an objective of bank supervision, although "supervision should aim to reduce the probability and impact of a bank failure, including by working with resolution authorities, so that when failure occurs, it is handled in an orderly manner" (BCBS 2012, 6).

Banking is highly dependent on maintaining public confidence. The ability to provide accurate and timely information to the public and stakeholders during times of instability and crisis is critical to preventing an erosion of confidence that can adversely affect banks' financial conditions. Adverse publicity about a bank can spill over to other banks. If not brought under control, it can lead to a broader erosion of public confidence that could pose systemic concerns.

Communications and crisis management protocols need to be crafted and formulated in advance, as there may be intense time pressure in times of crisis. Reactive approaches to crises usually result in unnecessarily expensive solutions and may have undesirable unintended consequences that could be avoided with planning.

The establishment, since 1997, of large, geographically disbursed banking organizations that operate across emerging Asia through multiple legal entities has made crisis communications particularly challenging. Some of these conglomerates operate separately organized banking companies in more than 10 countries. Domestic communications protocols must include supervisors and policy makers from each country in which the conglomerate operates. The complexity of some of these arrangements is challenging; keeping them up to date requires substantial ongoing effort.

In times of crisis, multiple governmental entities, such as central banks, finance ministries, deposit insurers, and other financial regulators, may divide or share decision making. Before a crisis, these parties should discuss how communications and decision making will occur, so that there is no uncertainty during a crisis. As players change over time, these discussions must be updated periodically.

Zamorski and Lim (2013) analyze 22 countries' FSAP assessments completed during 2012 and 2013. The countries included a diverse mix of size and developmental stages. Nine of the 22 were deemed to have systemically important finance sectors. The FSAPs identified fundamental deficiencies in many jurisdictions' crisis management and resolution arrangements and preparedness. Shortcomings were evident in the following areas:

(i) crisis management planning;

(ii) specification of roles of national authorities in a crisis;

(iii) legal powers to take various emergency actions in a crisis;

(iv) information-sharing arrangements with relevant authorities, both domestically and internationally;

(v) arrangements for providing emergency liquidity to banks;

(vi) specification of resolution strategies and options for failing or failed banks; and

(vii) crisis simulation exercises.

Many countries, including advanced economies, still did not have sufficient legal powers or crisis management capabilities or infrastructure to deal with financial instability or systemic crises.

A range of resolution strategies and options can be formulated in advance that will cover most eventualities. National authorities should seek the legal authority to deal with a broad range of 
potential crises and have discretion to implement resolution strategies appropriate to the circumstances.

Countries should periodically conduct simulation exercises to assess whether their crisis contingency plans will work, testing the efficacy of such arrangements under multiple scenarios. Formal interagency agreements should clarify the roles and responsibilities of different national authorities in a crisis. Countries should also introduce explicit deposit insurance schemes.

Crisis management and resolution arrangements should consider cross-border operations. Arrangements can include participation in cross-border crisis management groups and establishment of crisis communication systems among supervisors of multinational banking conglomerates.

In addition to monitoring bank financial data, bank supervisors monitor how exogenous risk factors may affect the safety and soundness of individual banks, the banking industry, and an economy's overall financial stability. This information is useful in helping set supervisory priorities and focus resources on external risk factors that pose the greatest threats to banks' safety and soundness. Central banks typically identify significant external risk factors in their financial stability reports.

Significant external risk factors to financial stability in Asia Pacific and other regions include the following:

(i) Expectations of the ending of accommodative monetary policy and the reduction or cessation of extraordinary policy actions by central banks in some advanced economies have already precipitated negative market reactions and volatility. Interest rate movements, exchange rate volatility, and capital outflows related to this risk could have negative consequences for some economies. Depending on the magnitude and velocity of changes, rising rates could adversely affect the prices of and markets for financial assets and real estate, inducing adverse knock-on effects. Unfavorable exchange rate shifts can have serious consequences for economies with substantial public and private sector debt denominated in foreign currency.

(ii) Sharply declining oil prices have positive and negative impacts, depending on national circumstances, the duration of lower prices, and other factors. Some economies, particularly net oil exporters, could be significantly adversely affected. Servicing their public debt levels and maintaining overall economic activity may be highly dependent on high prices.

(iii) A sustained period of extremely low interest rates induced sharp increases in sovereign debt, business borrowing, and consumer debt in many economies. A rise in interest rates could make it difficult to service this debt. Concerns about rapid expansion of consumer and residential mortgage debt have caused some jurisdictions to take macroprudential measures to prevent defaults and address real estate price bubbles financed by excessive borrowing.

(iv) Equity valuations in some markets may be out of line with economic values. Prices in these markets may be inflated by the global search for yield in the face of historically low interest rates. High levels of margin debt in some markets are an additional risk factor.

(v) Significant problems in some larger economies could cause financial instability that could spread across borders.

(vi) Shadow banking system risks vary across jurisdictions. They have generally not been a major concern in most of emerging Asia. The Financial Stability Board and other standards-setters have expressed concern that these risks are a potential source of 
systemic risk and regulatory arbitrage. Activities, primarily lending, may be moved to financial intermediaries with no or less stringent standards, potentially creating systemic risk (as occurred in the US during the crisis). Countries need to define the "regulatory perimeter" appropriate to their context: What nonbank financial intermediaries and other financial services should be regulated and supervised? What is the appropriate intensity of that supervision? Getting the balance right is important because soundly operated nonbank financial intermediaries help entrepreneurs and small and mediumsized enterprises until they are able to obtain bank credit.

\section{CONCLUSIONS AND RECOMMENDATIONS}

It has been more than 17 years ago since the last major episode of cross-border financial instability and banking crisis in emerging Asia. To extend this impressive record, bank supervisory authorities need to assess the effectiveness of their supervisory systems, infrastructure, and practices. This chapter highlights standards, practices, and lessons learned that may help them do so. If assessments disclose the need for changes, enhancements, or remedial actions, the relevant authorities should develop a plan to prioritize and implement them expeditiously.

The following actions are priorities for emerging Asia:

(i) Conduct self-assessments of compliance with the BCP, using outside experts as assessors if necessary, and promptly remedy instances of less than full compliance. Particularly important are CPs 12 and 13, which relate to consolidated supervision.

(ii) Ensure that legal powers exist to allow examination and inspection of all banks' affiliates, including unregulated entities. Laws governing transactions with affiliates must require that they conform to safe and sound banking practice to prevent contagion effects.

(iii) Ensure that the country's legal and regulatory frameworks support domestic and crossborder supervisory cooperation and information exchange, including the sharing of confidential supervisory information, between supervisors and other relevant authorities, such as deposit insurers. These powers are essential for ongoing consolidated supervision, crisis management, recovery, and resolution planning.

(iv) Ensure that surveillance methods and infrastructure can detect elevated risk at individual financial institutions (microprudential supervision) as well as increases in macroeconomic risk (macroprudential risk), such as real estate and other asset bubbles.

(v) Ensure that supervisory authorities are properly resourced and that staff have the necessary skills to supervise banks of the relevant size, business models, and complexity.

(vi) Ensure that the organization's supervisory culture and training approach develops examiners' ability to understand bank strategy and risk-taking rather than simply assess compliance.

(vii) Ensure that bank regulators adopt the international standards promulgated by the Basel Committee and other international standards-setters. Adoption of these standards promotes harmonization across jurisdictions and reduces opportunities for regulatory arbitrage or other efforts to circumvent regulations or forum shop.

(viii) Ensure that well-defined crisis management and resolution plans are in place so that nonviable banks can be resolved in an orderly manner. Domestic and foreign authorities should be clear on their roles and decision-making authority. The potential for crossborder resolutions greatly increases the complexity of crisis and contingency planning. 
Once plans are developed, a mechanism should be in place to keep them current and periodically tested, to ensure that they will work when needed.

(ix) Confirm that laws provide for timely interventions and resolutions for nonviable banks, in order to preserve public confidence and minimize losses to bank depositors, deposit insurers, other bank creditors, and taxpayers.

There is some intentional overlap in these recommendations. Investment of time and resources to perform the recommended assessments will provide valuable insights on ways to improve effectiveness and meet future challenges. Most important, this effort will help ensure a sound and stable banking system that supports local and regional financial stability. 


\section{REFERENCES}

Bank for International Settlements (BIS). 2001. Group of Ten: Consolidation in the Financial Sector. Basel.

Basel Committee on Banking Supervision (BCBS). 2012a. Principles for the Supervision of Financial Conglomerates. Joint Forum. September. Basel.

_. 2012b. Core Principles for Effective Banking Supervision. September. Basel.

Caruana, J. 2012. Dealing with Financial Systemic Risk: The Contribution of Macroprudential Policies. Panel remarks at the Central Bank of Turkey/G20 Conference on "Financial Systemic Risk." Istanbul. 27-28 September. http://www.bis.org/speeches/sp121002.htm (accessed 26 April 2015).

Claessens, S., S. R. Ghosh, and R. Mihet. 2013. Macro-Prudential Policies to Mitigate Financial System Vulnerabilities. Journal of International Money and Finance. 39: 153-85.

Financial Stability Board (FSB). 2013. An Overview of Policy Recommendations for Shadow Banking. Basel. $29 \quad$ August $29 . \quad$ http://www.financialstabilityboard.org/wpcontent/uploads/r_130829a.pdf (accessed on 26 April 2015).

International Monetary Fund (IMF). 2014a. The Financial Sector Assessment Program Factsheet. Washington. http://www.imf.org/external/np/exr/facts.htm (accessed 30 September 2014).

- 2014b. Financial Sector Assessment Program: Frequently Asked Questions. Washington, DC. http://www.imf.org/external/np/fsap/faq (accessed 7 August 2014).

IMF, BIS, and FSB. 2009. Report to the G-20 Finance Ministers and Governors, Guidance to Assess the Systemic Importance of Financial Institutions, Markets and Instruments: Initial Considerations. October. Washington, DC.

Laeven, L. and F. Valencia. 2012. Systemic Banking Database: An Update. IMF Working Paper. No. WP/12/163. Washington, DC: International Monetary Fund.

Lim, C., F. Columba, A. Costa, P. Kongsamut, A. Otani, M. Saiyid, T. Wezel, and X. Wu. 2011. Macroprudential Policy: What Instruments and How to Use Them? Lessons from Country Experiences. IMF Working Paper. No. WP/11/238. Washington, DC: International Monetary Fund.

Wihardja, M. M. 2013. Financial Integration Challenges in ASEAN beyond 2015. Economic Research Institute for ASEAN and East Asia Discussion Paper 2013-27. Jakarta: Centre for Strategic and International Studies.

Zamorski, M. .J. 2012. Post-Crisis Strategies to Enhance Prudential Supervision and Regulation to Promote Financial Stability. Panel remarks at the Centro de Estudios Monetarios Latinoamericanos - SEACEN Conference. Punta del Esta, Uruguay. 15 
November. http:/www.cemla.org/actividades/2012/2012-11-cemla-seacen/2012-11-cemlaseacen-12.pdf (accessed on 5 August 2015).

__ 2013a. The Basel Committee on Banking Supervision's September 2012 Revisions to Its Core Principles for Effective Banking Supervision. SEACEN Economic Letter No. 3. Kuala Lumpur: South East Asian Central Banks (SEACEN) Research and Training Centre. http://www.seacen.org/products/702001-100305-PDF.pdf (accessed 14 January 2013).

___ 2013b. Mitigating Systemic Risks: Externalities and Monetary Policy. Remarks at the SEACEN High-Level Seminar on Integrating Monetary Policies with Macroprudential Framework, South East Asian Central Banks. Bali, Indonesia. 7 November. http://www.seacen.org/products/702003-100348-PDF.pdf (accessed 7 November 2013).

Zamorski, M. J. and V. C.-S. Lim. 2013. Financial Stability Insights from Recent IMF/World Bank FSAP Assessments, SEACEN Financial Stability Journal 1. http://www.seacen.org/products/702002100320-PDF.pdf (accessed 29 October 2013). 


\section{Enhancing Bank Supervision in Asia: Lessons Learned from the Financial Crisis}

This study highlights the key attributes of effective supervision and regulation needed to enable developing Asia's banking systems to support sound, sustainable growth and development. The last major episode of cross-border financial instability and banking crisis in developing Asia occurred more than 17 years ago. To extend this impressive record of relative calm, bank supervisory authorities in the region need to assess their supervisory systems, infrastructure, and actual practices. If the assessment reveals that changes, enhancements, or remedial action are needed, a definitive plan should be crafted and implemented in a timely way.

\section{About the Asian Development Bank}

ADB's vision is an Asia and Pacific region free of poverty. Its mission is to help its developing member countries reduce poverty and improve the quality of life of their people. Despite the region's many successes, it remains home to the majority of the world's poor. $A D B$ is committed to reducing poverty through inclusive economic growth, environmentally sustainable growth, and regional integration.

Based in Manila, ADB is owned by 67 members, including 48 from the region. Its main instruments for helping its developing member countries are policy dialogue, loans, equity investments, guarantees, grants, and technical assistance. 